\title{
Competitive Degradation of Steroid Estrogens by Potassium Permanganate Combined with Ultrasound
}

\author{
Jing Deng ${ }^{1}$, Kai Tang ${ }^{1}$, Shijun Zhu ${ }^{1,2, *}$, Xiaoyan Ma ${ }^{1, *}$, Kejia Zhang ${ }^{3}$, Yali Song ${ }^{4}$, Xueyan Li ${ }^{5}$, \\ Qingsong $\mathrm{Li}^{6}{ }^{6}$, Zhenhua Liu ${ }^{7}$ and Kejin Zhou ${ }^{8}$ \\ Received: 19 October 2015; Accepted: 20 November 2015; Published: 4 December 2015 \\ Academic Editor: Rao Bhamidiammarri and Kiran Tota-Maharaj \\ 1 College of Civil Engineering and Architecture, Zhejiang University of Technology, Hangzhou 310014, \\ China; seudjing@163.com (J.D.); kaitang57@gmail.com (K.T.) \\ 2 School of Municipal and Environmental Engineering, Harbin Institute of Technology, Harbin 150001, China \\ 3 Department of Civil Engineering, Zhejiang University, Hangzhou 310058, China; zkj1025@163.com (K.Z.) \\ 4 School of Civil Engineering and Architecture, Zhejiang University of Science and Technology, \\ Hangzhou 310023, China; yali_song@sina.com \\ 5 School of Environmental Science and Engineering, Suzhou University of Science and Technology, \\ Suzhou 215009, China; lxyhit@sina.com \\ 6 Water Resources and Environmental Institute, Xiamen University of Technology, Xiamen 361005, \\ China; leetsingsong@sina.com \\ 7 Department of Municipal Engineering, Zhejiang University of Water Resource and Electric Power, \\ Hangzhou 361018, China; liuzhh@zjwchc.com \\ 8 Zhejiang Province Environmental Monitoring Center, Hangzhou 310012, China; zhoukj@163.com \\ * Correspondence: zhushijun_2010@126.com (S.Z.); mayaner620@163.com (X.M.); \\ Tel.: +86-571-8832-0180 (X.M.).
}

\begin{abstract}
The occurrence of natural estrogens including estrone (E1), 17ß-estradiol (E2), and synthetic $17 \alpha$-ethinylestradiol (EE2), which can be excreted by both humans and animals, and can enter the aqueous environment along with the discharge of domestic sewage, is a major concern since this may represent a serious health risk to humans even at extremely trace levels $\left(\mathrm{ng} \cdot \mathrm{L}^{-1}\right)$. Simultaneous degradation of three coexisting steroid estrogens (SEs) in aqueous solutions by coupled ultrasound and $\mathrm{KMnO}_{4}$ systems $\left(\mathrm{KMnO}_{4} /\right.$ ultrasound) were investigated to find out whether there is a competitive degradation of multiple contaminants or not. Results indicate that the degradation ratios of target SEs were all more than $50 \%$ after 120 min reaction contact, greatly enhanced when compared with the single $\mathrm{KMnO}_{4}\left(2 \mathrm{mg} \cdot \mathrm{L}^{-1}\right)$ oxidation of E2 (37.0\%), EE2 (34.4\%), and E1 $(34.0 \%)$, and the single sonochemical oxidation of E2 (37.1\%), EE2 (31.1\%), and E1 (29.7\%). In the adopted processes, the degradations of SEs fit the first-order kinetic reaction, with different reaction rates. Kinetic parameters revealed there was little difference between coexisting SEs, which means there was almost no competitive degradation. The removal efficiency and degradation rate of SEs in natural water was higher than those in pure water, which suggested that the coupled $\mathrm{KMnO}_{4} / \mathrm{ultrasound}$ technology had prospective applications in the removal of complex contaminants in actual drinking water treatment.
\end{abstract}

Keywords: coexisting pollutant; competitive degradation; drinking water treatment; $\mathrm{KMnO}_{4} / \mathrm{ultrasound}$; steroid estrogens

\section{Introduction}

Steroid estrogens (SEs) are kinds of micropollutants detected in aqueous circumstances that are attracting wide concern since they have ten thousand to ten million times the estrogenic activity of other endocrine disrupting chemicals (EDCs) [1]. SEs, characterized with polytype, prevalent 
distribution, low concentrations, great risk, and difficult degradation, may inhibit or undermine the normal function of endocrine and other vital systems through interfering with synthesis, secretion, transport, binding, action or elimination of natural hormones in the body which are responsible for the maintenance of homeostasis, adjustment, reproduction, development, and/or behavior [2-8]. Steroid estrogen (SEs) including natural estrogenic steroids such as estrone (E1), 17 $\beta$-estradiol (E2), estriol (E3), and synthetic steroid $17 \alpha$-ethynylestradiol (EE2) in aqueous environments are organics of tetracyclic molecules which have a benzene ring and conjugated double bond with a molecular weight between 200 and 400, normally [9].

Natural steroid estrogens can enter the aqueous environment through the discharge of the wastewater-containing metabolism of humans and livestock herding, such as urine and excrement. Synthetic steroids usually originate from medication (e.g., oral contraceptive) produced in pharmaceutical enterprises with industrial effluents emission. Recently, SEs have been detected in sewage, surface water, underground water, and even sources of drinking water [10-12]. An extensive survey of steroid estrogens was conducted for sources water of Hangzhou City, China, and the results showed traces of EE2 (1.17-3.35 $\left.\mathrm{ng} \cdot \mathrm{L}^{-1}\right)$, and E2 (0.132 $\left.\mathrm{ng} \cdot \mathrm{L}^{-1}\right)$ existing in Qiantang River [10]. In the north of Germany, estrogens were detected in the range of $0.2-0.6 \mathrm{ng} \cdot \mathrm{L}^{-1}$ for E1 and $0.2-2.1 \mathrm{ng} \cdot \mathrm{L}^{-1}$ for E2. E1, E2 and EE2 were found in a reservoir of source water in Shanghai with a concentration range of 1.0-110.0, 0.0-90.0, and 0.8-80.0 ng. $\mathrm{L}^{-1}$ respectively [12]. Those SE compounds in source water may penetrate conventional treatment units (e.g., coagulation/sedimentation, filtration, and chlorination), and then finally get to the faucet of users, bringing with them potential negative effects. Therefore, it is important to find the proper methods to reduce the contamination arousing public concern.

Activated carbon (AC) as an effective adsorbent is obviously efficient for the removal of SEs at high concentrations [13-17]. However, when source water is contaminated by complex contaminants besides SEs, the adsorption efficiency to extracted SEs will be influenced by the matrix, such as NOM or other micropollutants, so longer contact times and a large quantity of AC should be needed to get favorable adsorption [17]. Biological degradation and enzymatic reactions were more often employed in the removal of SEs that were not suitable for drinking water treatment, usually in the sewage treatment process due to the slow reduction rates, long treatment time, and incomplete decomposition [18]. Recently, there have been numerous studies on the removal of estrogens through chemical oxidation [19], advanced oxidation [20-22], and photocatalysis [23] in combination with UV and strong oxidizers [24], but the most focus is on the analysis of the degradation rate, efficiencies, and influential factors for a single target pollutant while ignoring simultaneous degradation of pollutants in multiple contamination matrices. The objective here is to summarize the simultaneous or probable competitive elimination of coexisting SEs in the $\mathrm{KMnO}_{4} / \mathrm{ultrasound}$ treatment process by using simplified models.

\section{Materials and Methods}

\subsection{Chemicals}

Standard estrone (E1), 17 $\beta$-estradiol (E2), and $17 \alpha$-ethinyl estradiol (EE2) were purchased from Sigma-Aldrich. Methanol (HPLC grade) was obtained from Tedia, and acetonitrile (HPLC grade) was supplied by Merck. Pure water was obtained through the Milli-pore equipment. The $\mathrm{KMnO}_{4}$ and sodium thiosulfate were commercially available analytical-grade products.

\subsection{Ultrasonic Apparatus and Reactor Facility}

The ultrasonic generator FS-300 (Sonxi, Shanghai, China) can operate either continuously or in a pulsed mode at a fixed frequency of $20 \mathrm{kHz}$ and a variable power output of up to $300 \mathrm{~W}$. Ultrasound irradiation was emitted through a tip $1 \mathrm{~cm}$ in diameter. The tip was fixed on a tripod, which was installed centrally in a $10 \mathrm{~L}$ cylindrical reactor to make sure that the tip immersed $5 \mathrm{~cm}$ away from the bottom.

The reactor was operated in a recirculation mode at a flow velocity of $2 \mathrm{~L} \cdot \mathrm{min}^{-1}$ fixed by a pump installed outside of the reactor, which plays a role of blending and stirring. Plastic tubes were fixed 
around the external part of the reactor, and tap water was kept running through during experiments to maintain a constant temperature.

\subsection{Analytical Methods}

A 12 solid phase extraction device (CNW, USA) with C18 solid phase extraction columns (CNW, USA) was used to extract SEs from aqueous solutions. Agilent1200 HPLC with an ultraviolet detector set at $220 \mathrm{~nm}$ was used to determine the concentrations of SEs in samples with an Eclipse XDB-C18 column $(5 \mu \mathrm{m}, 46 \times 150 \mathrm{~mm}$, USA). Sample injections were achieved by an SIJ-20A auto injection system. The mobile phase water/acetonitrile (50/50, v/v) was run in an isocratic mode at a constant flow rate of $0.8 \mathrm{~mL} \cdot \mathrm{min}^{-1}$, and the column was maintained at a constant of $30{ }^{\circ} \mathrm{C}$. The injection volume was $20 \mu \mathrm{L}$. Liquid chromatography of three kinds of steroid estrogens is shown in Figure 1. The peaks of SEs were shown in a sequence of E2, EE2, and E1, and the retention times were 5.0, 6.1, and $7.2 \mathrm{~min}$, respectively.

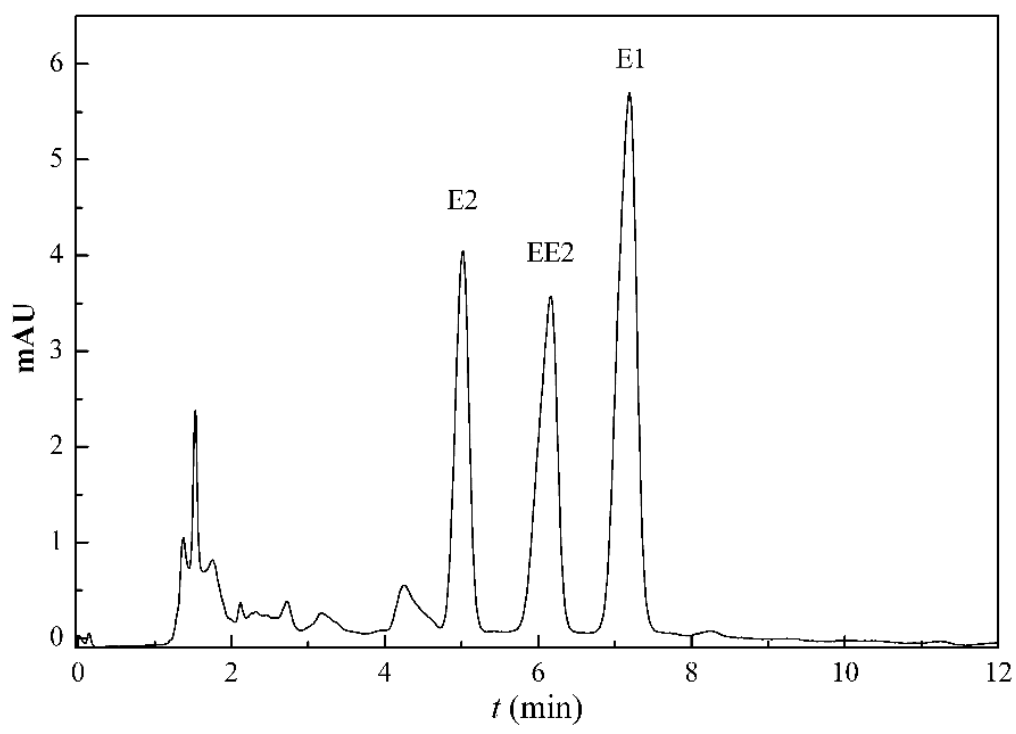

Figure 1. Liquid chromatography of three kinds of steroid estrogens.

\subsection{Experimental Procedure}

Solutions of SEs were prepared by deionized water in the reactor, adjusted to optimum $\mathrm{pH}$ 7.6 with $0.1 \mathrm{~mol} \cdot \mathrm{L}^{-1} \mathrm{HCl}$ and $0.1 \mathrm{~mol} \cdot \mathrm{L}^{-1} \mathrm{NaOH}$, according to the previous description of Ma et al. [25]. Samples were collected to determine the initial concentration $\left(\mathrm{C}_{0}\right)$ of SEs after sufficient mixture. Except those which took temperature variation into consideration, the experiments were performed at room temperature $\left(23 \pm 2{ }^{\circ} \mathrm{C}\right)$. Once the oxidation process was started; sequence samples $(100 \mathrm{~mL})$ were collected into beakers $(150 \mathrm{~mL})$ at 2, 5, 10, 15, 30, 50, 80, and 120 min intervals with substantial sodium thiosulphate immediately added to quench the reaction. Residual concentrations were analyzed as soon as possible after pretreatment, and were otherwise stored at $-4{ }^{\circ} \mathrm{C}$ in darkness.

Water samples $(100 \mathrm{~mL})$ were first concentrated by solid phase extraction (SPE) using C18 cartridges $(3 \mathrm{~mL}, 500 \mathrm{mg}$ ), which were pre-conditioned with $10 \mathrm{~mL}$ of methanol, $10 \mathrm{~mL}$ of acetonitrile, and $20 \mathrm{~mL}$ of pure water in sequence at a flow of $3 \mathrm{~mL} \cdot \mathrm{min}^{-1}$. After samples had been loaded entirely, the cartridges were then eluted with $3 \mathrm{~mL}$ of acetonitrile. The eluents were dried under a gentle nitrogen purge, then redissolved in $1 \mathrm{~mL}$ acetonitrile, and finally were analyzed by HPLC. The residual water samples were stored at $-4{ }^{\circ} \mathrm{C}$ in darkness to be measured for other water quality parameters. The single ultrasound process was applied at $210 \mathrm{~W}$ power and $20 \mathrm{kHz}$ frequency. The same parameters were adopted in combined $\mathrm{KMnO}_{4} / \mathrm{ultrasound}$ process and the $\mathrm{KMnO}_{4}$ dosage was designed to be $2 \mathrm{mg} \cdot \mathrm{L}^{-1}$.

\section{Results and Discussion}




\subsection{Simultaneous Degradation of SEs by Potassium Permanganate Oxidation}

Figure 2 shows the simultaneous degradation kinetics models of mixed E1, E2, and EE2, with initial concentrations of $13,17,25 \mu \mathrm{g} \cdot \mathrm{L}^{-1}$ respectively, in single potassium permanganate oxidation processes with dosages of 2,4 , and $6 \mathrm{mg} \cdot \mathrm{L}^{-1}$.
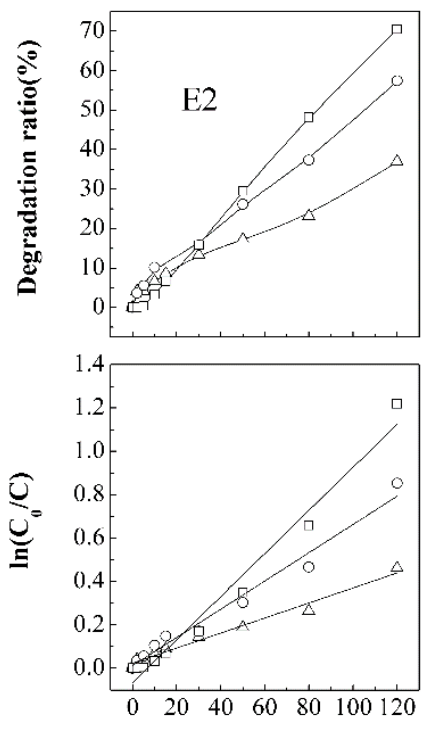
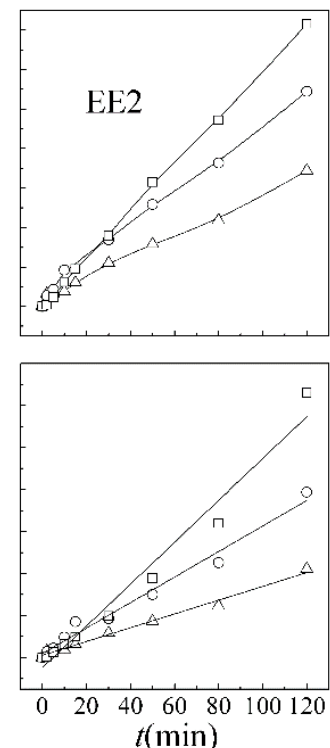
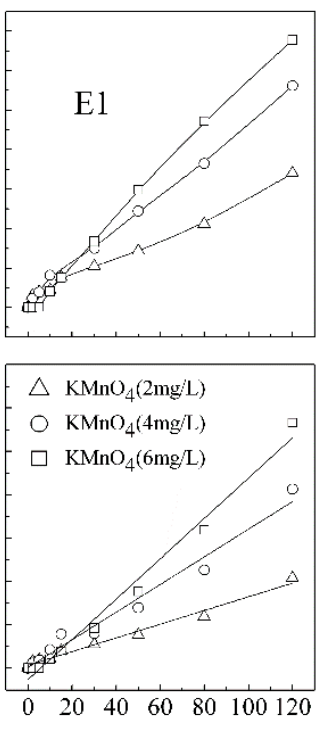

Figure 2. Degradation curves and first order kinetic models of SEs under different dosage of potassium permanganate.

In coexisting competitive degradation systems, E1, E2, and EE2 respectively had low removal rates of $37.0 \%, 34.4 \%$, and $34.0 \%$ after 120 min of contact time with a minimum $\mathrm{KMnO}_{4}$ dosage of $2 \mathrm{mg} \cdot \mathrm{L}^{-1}$. The results suggested that E2 could be slightly better degraded than the other two SEs at the degradation level. When the amount of oxidant increased to $4 \mathrm{mg} \cdot \mathrm{L}^{-1}$, the removal efficiencies of SEs obviously enhanced, to approximately 57.4\% (E2), 54.5\% (EE2), and 56.2\% (E1). With $\mathrm{KMnO}_{4}$ dosages continually increasing to $6 \mathrm{mg} \cdot \mathrm{L}^{-1}$, the removal efficiencies increased up to $71.6 \%(\mathrm{E} 2), 70.5 \%$ (EE2), and $67.8 \%$ (E1). The results revealed a positive relationship between removal efficiencies of SEs and $\mathrm{KMnO}_{4}$ dosage. The contaminants removal mechanisms by $\mathrm{KMnO}_{4}$ include conventional oxidation and catalysis/adsorption generated by the reaction products of $\mathrm{Mn}^{2+}$ and $\mathrm{MnO}_{2}$ [26]. Numerous studies demonstrated that $\mathrm{pH}$ had a significant effect on the redox potential of permanganate with $1.51 \mathrm{~V}, 0.588 \mathrm{~V}$, and $0.564 \mathrm{~V}$ for acidic, neutral, and alkaline conditions, respectively $[27,28]$. The following Equations (1)-(3) apply:

$$
\begin{gathered}
\mathrm{MnO}_{4}^{-1}+8 \mathrm{H}^{+}+5 \mathrm{e}^{-}=\mathrm{Mn}^{2+}+4 \mathrm{H}_{2} \mathrm{O} \\
\mathrm{MnO}_{4}^{-1}+2 \mathrm{H}_{2} \mathrm{O}+3 \mathrm{e}^{-}=\mathrm{MnO}_{2}+4 \mathrm{OH}^{-} \\
2 \mathrm{MnO}_{4}^{-1}+3 \mathrm{Mn}^{2+}+2 \mathrm{H}_{2} \mathrm{O}=5 \mathrm{MnO}_{2}+4 \mathrm{H}^{+}
\end{gathered}
$$

$\mathrm{MnO}_{2}$ as a catalyst produced during reaction improved the oxidation rate, and the colloids compounded by $\mathrm{MnO}_{2}$ had a larger surface area to adsorb organisms in aqueous systems [22,29].

Under simulated combination pollutant conditions, the degradation of SEs follows pseudo-first-order reaction kinetics under various $\mathrm{KMnO}_{4}$ doses, and parameters are shown in Table 1. In the $\mathrm{KMnO}_{4}$ oxidation process, considering the removal efficiency, reaction rate, and half-life, superior degradation of E2 was recognized and supposed to be attributed to the lower initial concentration.

Since $\mathrm{KMnO}_{4}$ can induce color into water, the lowest $\mathrm{KMnO}_{4}$ dosage $\left(2 \mathrm{mg} \cdot \mathrm{L}^{-1}\right)$ was selected in the subsequent experiments for further understanding of the simultaneous estrogen removal in the $\mathrm{KMnO}_{4} /$ ultrasound system. 
Table 1. Parameters of the kinetic model of degradation of SEs under single potassium permanganate treatment with different dosages.

\begin{tabular}{cccccc}
\hline $\begin{array}{c}\text { Steroid } \\
\text { Estrogens }\end{array}$ & $\begin{array}{c}\mathbf{K M n O}_{4} / \\
\left(\mathbf{m g} \cdot \mathbf{L}^{-1}\right)\end{array}$ & Kinetic Equation & $\begin{array}{c}\text { Reaction Rate } \\
\text { Constant } \\
\mathbf{K} / \mathbf{m i n}^{-1}\end{array}$ & $\mathbf{R}^{2}$ & $\begin{array}{c}\text { Half-Life } \\
\boldsymbol{t}_{1 / 2} / \mathbf{m i n}\end{array}$ \\
\hline \multirow{2}{*}{ E2 } & 2 & $\ln \left(\mathrm{C}_{0} / C\right)=0.0035 t+0.025$ & 0.0035 & 0.978 & 193 \\
& 4 & $\ln \left(\mathrm{C}_{0} / C\right)=0.0065 t+0.013$ & 0.0065 & 0.975 & 105 \\
& 6 & $\ln \left(\mathrm{C}_{0} / C\right)=0.0099 t-0.065$ & 0.0099 & 0.974 & 76 \\
\hline \multirow{2}{*}{ EE2 } & 2 & $\ln \left(\mathrm{C}_{0} / C\right)=0.0033 t+0.011$ & 0.0033 & 0.988 & 208 \\
& 4 & $\ln \left(\mathrm{C}_{0} / C\right)=0.0061 t+0.090$ & 0.0061 & 0.979 & 99 \\
& 6 & $\ln \left(\mathrm{C}_{0} / C\right)=0.0100 t-0.049$ & 0.0100 & 0.970 & 74 \\
\hline \multirow{2}{*}{ E1 } & 2 & $\ln \left(\mathrm{C}_{0} / C\right)=0.0032 t+0.015$ & 0.0032 & 0.980 & 215 \\
& 4 & $\ln \left(\mathrm{C}_{0} / C\right)=0.0064 t+0.049$ & 0.0064 & 0.973 & 108 \\
& 6 & $\ln \left(\mathrm{C}_{0} / C\right)=0.0093 t-0.052$ & 0.0093 & 0.984 & 80 \\
\hline
\end{tabular}

\subsection{Simultaneous Degradation of SEs by Ultrasound}

Numerous researchers indicated that the organic matters could be removed by single ultrasound to various degrees. Influencing factors were reported to have a strong effect on degradation of organic contaminants [30-34].

Removal efficiencies of $37.1 \%$ (E1), 31.1\% (E2), and 29.7\% (EE2) were obtained by using single ultrasound irradiation as shown in Figure 3. Results were obtained after $120 \mathrm{~min}$ of contact, and the degradation of SEs fitted pseudo-first-order reaction kinetics. Sonochemical reaction involved the complex phenomenon of oxidation derived from cavitations. Cavitation bubbles grow from existing gas nuclei, oscillate, and collapse to generate high temperatures and pressures that induce target compound pyrolysis inside the bubble/or at the bubble-liquid interface at exceedingly short times [25,35]. Mechanisms of ultrasonic degradation of organic contaminants had been proposed as pyrolytic decomposition, hydroxyl radical oxidation, plasma chemistry, and supercritical water oxidation [35]. When the sound waves pass through the liquid, they create cavities due to oscillating acoustic pressures. The dissolved gases, organic compounds, and water vapor can diffuse into the cavities from bulk solutions. These cavities grow in size and ultimately implode, generating temperatures as high as $5200 \mathrm{~K}$ and pressures higher than $1000 \mathrm{~atm}$ inside the collapsing cavity, and about $1900 \mathrm{~K}$ in the interfacial region between the solution and the collapsing bubble. The destruction of organic pollutants occurs via several mechanisms. The organic pollutant inside the cavity and in the interfacial region (cavity-liquid) can undergo thermal degradation (pyrolysis or combustion reactions if oxygen is present during the implosion). Another mechanism is that free radicals $(\bullet \mathrm{OH}$, $\bullet \mathrm{H}, \bullet \mathrm{HO}_{2}$ ) formed due to thermolysis of the water molecules can react with the organics in the interfacial region or in the bulk solution near the interface [36]. Free radicals can subsequently react with steroid estrogens in the aqueous phase, hydroxyl radicals $(\bullet \mathrm{OH})$ as the representative, are strong oxidizers with a standard redox potential $\left(E_{0}\right)$ of $2.80 \mathrm{eV}$. As the circumstance of temperature and $\mathrm{pH}$ is fixed, the organic contaminants are removed mainly depending on the acoustic cavitation pyrolysis due to a few free radicals produced by single ultrasound in the pure water model. Furthermore, acoustic cavitations were generated on a tiny scale of ultrasonic source, and the energy utilization ration is merely $15 \%$ [37].

It can be recognized from Figure 3a,d that E2 takes advantage with a higher degradation ratio constant over EE2 and E1, which is more apparent in the sonic degradation process than in $\mathrm{KMnO}_{4}$ oxidation. Considering the mechanism of ultrasound irradiation, hydrophobicity might play an important role in the degradation, besides initial concentration. Hydrophobicity has a positive effect on the pyrolysis reaction [36]. Due to their hydrophobicity, the estrogens would tend to diffuse into the cavity-liquid interface. The supercritical environment produced in the interfacial region would 
increase the solubility of estrogens. Three target estrogens are hydrophobic compounds, with low octanol-water partition coefficients (logKow). The hydrophobicity of E2 is slightly stronger than EE2 and E1, and thus it is easier to enter into the cavitation bubbles and be decomposed in the coexisting system.

The emission frequency of the ultrasonic generator used in this experiment was $20 \mathrm{kHz}$, which was much lower than those reported by other researchers (ranging from 200 to $1200 \mathrm{kHz}$ ). The increase of frequencies could definitely improve the degradation ratio of organic contaminants because of more energy consumption [38-40]. Above results showed that single ultrasound or $\mathrm{KMnO}_{4}$ were inefficient in SEs degradation, while combined $\mathrm{KMnO}_{4} /$ ultrasound could improve the degradation of SEs significantly $[25,41]$.
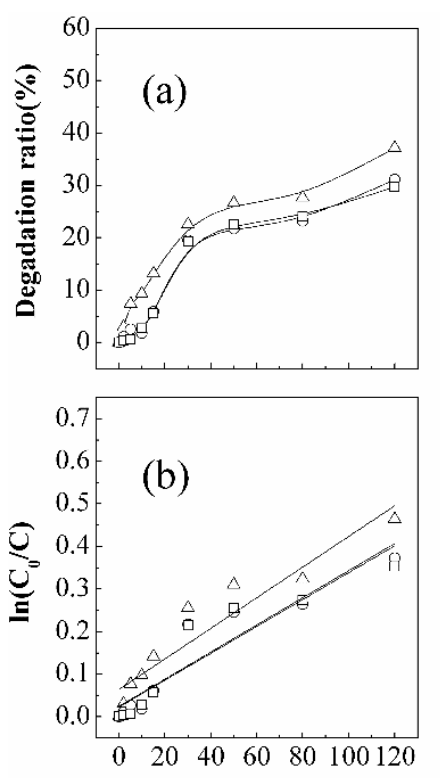
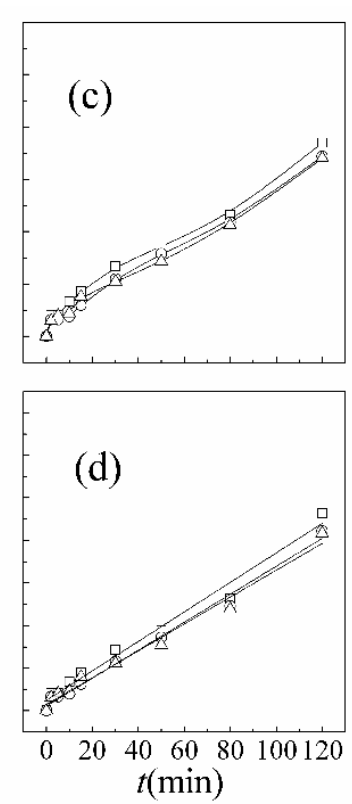
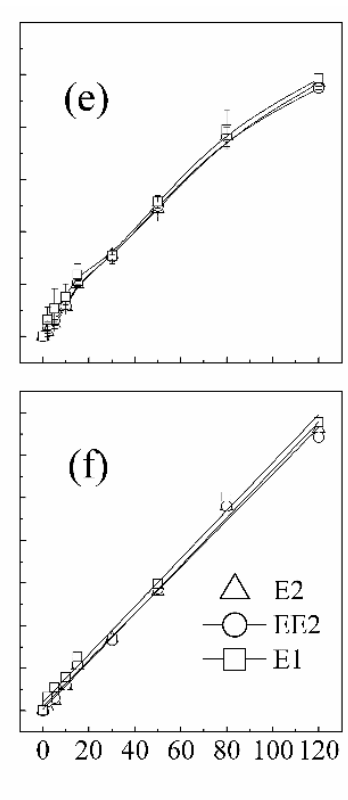

Figure 3. Degradation curves and first order kinetic models of SEs in different treatment processes ((a), (b) single ultrasound; (c), (d) single $\mathrm{KMnO}_{4}$; (e), (f) combined $\mathrm{KMnO}_{4} /$ ultrasound).

\subsection{Simultaneous Degradation of SEs by $\mathrm{KMnO}_{4} /$ Ultrasound}

\subsubsection{Degradation Efficiency of SEs in Different Treatment Process}

Degradation of SEs fit pseudo-first-order kinetics in each treatment process. The removal curves for the different treatment processes are shown in Figure 3. After a 120 min reaction, the degradation efficiencies of E2 (49.2\%), EE2 (48.4\%), and E1 (47.4\%) by ultrasound/ $\mathrm{KMnO}_{4}$ were higher than those by single treatment processes, which reveal more effectiveness of combined ultrasound $/ \mathrm{KMnO}_{4}$ process.

$$
-\frac{d C}{d t}=k C \Leftrightarrow \ln \frac{C_{0}}{C}=k t
$$

where $k$ is an apparent rate constant, incorporating the constant concentration of oxidizing agents. The rate constants of oxidation $\left(k_{\mathrm{KMnO}_{4}}\right)$, ultrasonic irradiation $\left(k_{\mathrm{US}}\right)$, and their combination $\left(k_{\mathrm{US} / \mathrm{KMnO}_{4}}\right)$ can be calculated according to Equation (4). The degree of synergy $\mathrm{S}$ can then be assessed as follows [30]:

$$
\% \mathrm{~S}=\frac{k_{\mathrm{US} / \mathrm{KMnO}_{4}}-\left(k_{\mathrm{KMnO}_{4}}+k_{\mathrm{US}}\right)}{k_{\mathrm{US} / \mathrm{KMnO}_{4}}} \times 100
$$

In this case, $S<0$ indicates that there is not a good synergy between them, possibly due to the low frequencies of the ultrasonic generator in the experiments. It is generally known that radical 
generation by ultrasound is more effective at higher ultrasound frequencies. At lower frequencies, the cavitation effect is the dominant factor. Frontistis et al. investigated the photocatalytic $\left(\mathrm{UV}-\mathrm{A} / \mathrm{TiO}_{2}\right)$ degradation of 17-ethynylestradiol (EE2) in environmental matrices, and showed that there is a two-way synergy between them $(S=44.3 \%)$, while the horn-type sonicator operating at $80 \mathrm{kHz}$ was employed for sonophotocatalytic experiments [42].

Reaction rate constants in Table 2 manifest that there are minor differences between the degradation rate of E1, E2, and slightly lower of EE2. Accordingly, the results elucidate that there is almost no obvious competitive degradation of target SEs under the condition of lower initial concentrations.

The mechanisms of the synergetic effect of ultrasounds and $\mathrm{KMnO}_{4}$ could be explained as follows Ma et al. [41].

$\mathrm{H}_{2} \mathrm{O}$ produces $\mathrm{H}_{2} \mathrm{O}_{2}$, which undergoes partial dissociation in the presence of ultrasound.

$$
\mathrm{H}_{2} \mathrm{O}_{2}+\mathrm{H}_{2} \mathrm{O}-\mathrm{HO}_{2}^{-}+\mathrm{H}_{3} \mathrm{O}^{+}
$$

The $\mathrm{H}_{3} \mathrm{O}^{+}$makes the solution acidic, which improves the generation of $\bullet \mathrm{OH}$ decomposed by $\mathrm{KMnO}_{4}$.

$$
\begin{gathered}
4 \mathrm{MnO}_{4}^{-1}+4 \mathrm{H}^{+}-4 \mathrm{MnO}_{2} \uparrow+2 \mathrm{H}_{2} \mathrm{O}+3 \mathrm{O}_{2} \\
\left.\left.\left.\mathrm{O}_{2}+\right)\right)\right)-\bullet \mathrm{O}+\bullet \cdot \mathrm{O} \\
\mathrm{O} \bullet+\mathrm{H}_{2} \mathrm{O}-\bullet \mathrm{OH}+\bullet \mathrm{OH}
\end{gathered}
$$

Furthermore, the redox reaction occurs between $\mathrm{H}_{2} \mathrm{O}_{2}$ and $\mathrm{KMnO}_{4} . \mathrm{Mn}^{2+}$ and $\mathrm{MnO}_{2}$, produced in the reaction, have a strong catalytic effect on cavitations, thus promoting further degradation of the organic contaminants. Accordingly, $\mathrm{KMnO}_{4}$ can improve the ultrasound to produce $\bullet \mathrm{OH}$ in an aqueous environment.

$$
\begin{gathered}
2 \mathrm{MnO}_{4}^{-1}+5 \mathrm{H}_{2} \mathrm{O}_{2}+6 \mathrm{H}^{+}-2 \mathrm{Mn}^{+}+5 \mathrm{O}_{2}+8 \mathrm{H}_{2} \mathrm{O} \\
2 \mathrm{MnO}_{4}^{-1}+3 \mathrm{H}_{2} \mathrm{O}_{2}-2 \mathrm{MnO}_{2}+3 \mathrm{O}_{2}+2 \mathrm{OH}^{-}+2 \mathrm{H}_{2} \mathrm{O}
\end{gathered}
$$

\begin{tabular}{|c|c|c|c|c|c|}
\hline $\begin{array}{c}\text { Steroid } \\
\text { Estrogens }\end{array}$ & $\begin{array}{c}\text { Treatment } \\
\text { Technologies }\end{array}$ & Kinetic Equation & $\begin{array}{l}\text { eaction Rate } \\
\text { Constant } \\
\mathrm{K} / \mathrm{min}^{-1}\end{array}$ & $\mathbf{R}^{2}$ & $\begin{array}{c}\text { Half-Life } \\
t_{1 / 2} / \mathrm{min}\end{array}$ \\
\hline \multirow{3}{*}{ E2 } & $\mathrm{KMnO}_{4}\left(2 \mathrm{mg} \cdot \mathrm{L}^{-1}\right)$ & $\ln \left(\mathrm{C}_{0} / C\right)=0.0035 t+0.025$ & 0.0035 & 0.978 & 191 \\
\hline & Pure ultrasound & $\ln \left(\mathrm{C}_{0} / C\right)=0.0036 t+0.064$ & 0.0036 & 0.888 & 175 \\
\hline & $\mathrm{KMnO}_{4} /$ ultrasound & $\ln \left(\mathrm{C}_{0} / C\right)=0.0056 t+0.003$ & 0.0056 & 0.996 & 123 \\
\hline \multirow{3}{*}{ EE2 } & $\mathrm{KMnO}_{4}\left(2 \mathrm{mg} \cdot \mathrm{L}^{-1}\right)$ & $\ln \left(\mathrm{C}_{0} / C\right)=0.0033 t+0.011$ & 0.0033 & 0.988 & 207 \\
\hline & Pure ultrasound & $\ln \left(\mathrm{C}_{0} / C\right)=0.0032 t+0.024$ & 0.0032 & 0.874 & 210 \\
\hline & $\mathrm{KMnO}_{4} /$ ultrasound & $\ln \left(\mathrm{C}_{0} / \mathrm{C}\right)=0.0055 t+0.010$ & 0.0055 & 0.994 & 125 \\
\hline \multirow{3}{*}{ E1 } & $\mathrm{KMnO}_{4}\left(2 \mathrm{mg} \cdot \mathrm{L}^{-1}\right)$ & $\ln \left(\mathrm{C}_{0} / C\right)=0.0032 t+0.015$ & 0.0032 & 0.980 & 212 \\
\hline & Pure ultrasound & $\ln \left(\mathrm{C}_{0} / C\right)=0.0032 t+0.023$ & 0.0032 & 0.852 & 210 \\
\hline & $\mathrm{KMnO}_{4} /$ ultrasound & $\ln \left(\mathrm{C}_{0} / C\right)=0.0056 t+0.020$ & 0.0056 & 0.993 & 120 \\
\hline
\end{tabular}

Permanganate was usually applied as a pre-oxidant in the drinking water treatment processes. The $\mathrm{MnO}_{2}$ as a type of light yellow granule, can be removed easily in the following traditional treatment units, e.g., coagulation/sedimentation, filtration, etc. Considering the residual manganese and color problem, dosages of permanganate were always controlled to under a certain value.

Table 2. Degradation kinetic parameters of SEs under different processes. 


\subsubsection{Effects of Initial Concentration of SEs}

Sample solutions of mixed SEs were prepared in concentrations of approximately 50, 100, and $500 \mu \mathrm{g} \cdot \mathrm{L}^{-1}$. The impact of the initial concentration on the SEs' simultaneous degradation in a $\mathrm{KMnO}_{4} /$ ultrasound process were investigated, with $\mathrm{KMnO}_{4}\left(2 \mathrm{mg} \cdot \mathrm{L}^{-1}\right)$, ultrasonic power $(210 \mathrm{~W})$ and a frequency of $(20 \mathrm{kHz})$. Degradation kinetic models of SEs under different initial concentrations were showed in Table 3.

Table 3. Parameters of the degradation kinetic model of SEs under different initial concentrations.

\begin{tabular}{|c|c|c|c|c|c|}
\hline $\begin{array}{c}\text { Steroid } \\
\text { Estrogens }\end{array}$ & $\begin{array}{c}\text { Initial } \\
\text { Concentration } \\
\left(\mu \mathrm{g} \cdot \mathrm{L}^{-1}\right)\end{array}$ & Kinetic Equation & $\begin{array}{c}\text { Reaction Rate } \\
\text { Constant K/min } \\
-1\end{array}$ & $\mathbf{R}^{2}$ & $\begin{array}{c}\text { Half-Lif } \\
t_{1 / 2} / \mathrm{min}\end{array}$ \\
\hline \multirow{3}{*}{ E2 } & 50 & $\ln \left(\mathrm{C}_{0} / C\right)=0.0056 t+0.003$ & 0.0056 & 0.996 & 123 \\
\hline & 100 & $\ln \left(\mathrm{C}_{0} / C\right)=0.0041 t+0.020$ & 0.0041 & 0.984 & 163 \\
\hline & 500 & $\ln \left(\mathrm{C}_{0} / C\right)=0.0029 t+0.019$ & 0.0029 & 0.972 & 230 \\
\hline \multirow{3}{*}{ EE2 } & 50 & $\ln \left(\mathrm{C}_{0} / C\right)=0.0055 t+0.010$ & 0.0055 & 0.994 & 125 \\
\hline & 100 & $\ln \left(\mathrm{C}_{0} / C\right)=0.0039 t+0.032$ & 0.0039 & 0.964 & 169 \\
\hline & 500 & $\ln \left(\mathrm{C}_{0} / C\right)=0.0024 t+0.022$ & 0.0024 & 0.944 & 212 \\
\hline \multirow{3}{*}{ E1 } & 50 & $\ln \left(\mathrm{C}_{0} / C\right)=0.0056 t+0.020$ & 0.0056 & 0.993 & 120 \\
\hline & 100 & $\ln \left(\mathrm{C}_{0} / C\right)=0.0038 t+0.042$ & 0.0038 & 0.959 & 172 \\
\hline & 500 & $\ln \left(\mathrm{C}_{0} / C\right)=0.0024 t+0.025$ & 0.0024 & 0.965 & 282 \\
\hline
\end{tabular}

As shown in Figure 4, when the initial concentration of SEs is $100 \mu \mathrm{g} \cdot \mathrm{L}^{-1}$, the degradation efficiencies of E2, EE2, and E1 are 38.3\%, 36.6\%, and 36.5\%, respectively, with little difference in the coexisting system after 120-min-contact. However, it was observed that E2, EE2, and E1 were only removed by $28.8 \%, 24.4 \%$, and $24.8 \%$, respectively, when the initial concentration of SEs increases to about $500 \mu \mathrm{g} \cdot \mathrm{L}^{-1}$ with the same reaction time. Simultaneous degradation of the coexisting combinations of estrogens in $\mathrm{KMnO}_{4} / \mathrm{ultrasound}$ system follows the apparent first-order kinetics shown in Figure 4. The degradation ratio and removal rate decrease with increasing initial concentrations of estrogens, which is similar to the conclusions of $\mathrm{He}$ et al. who used combined $\mathrm{Fe}(\mathrm{III}) / \mathrm{H}_{2} \mathrm{O}_{2}$ technology [43]. Low concentration favors the degradation of SEs. The reason may be due to the low concentration accompanied by preferable contact with free hydroxyl radicals $(\bullet \mathrm{OH})$ and little oxidant demand.
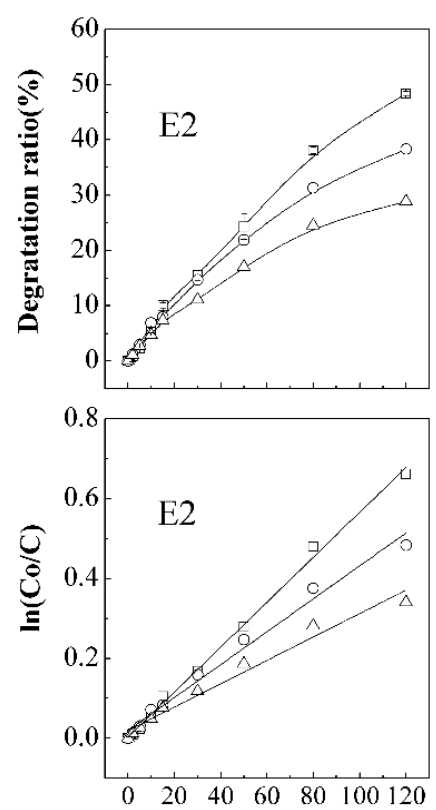
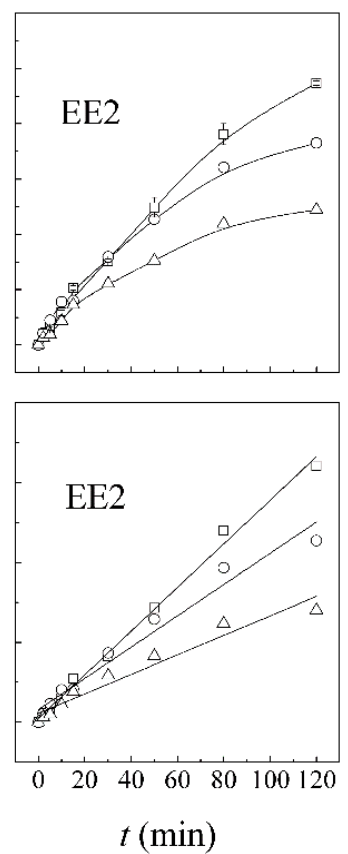
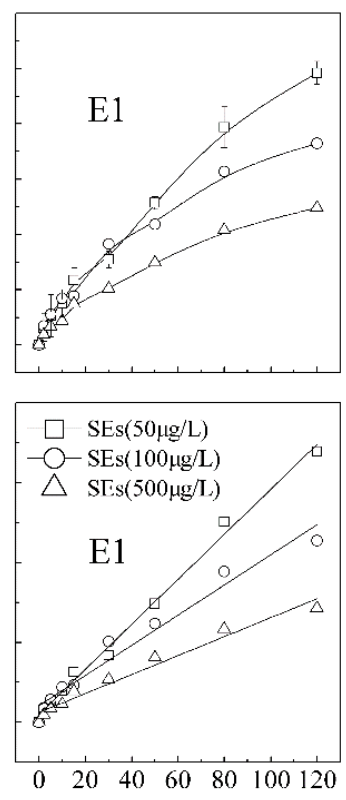

$\begin{array}{lllllll}0 & 20 & 40 & 60 & 80 & 100 & 120\end{array}$

Figure 4. Degradation curves and first order kinetic models of SEs in combined processes under different initial concentrations. 


\subsubsection{Analysis of Competitive Degradation of Coexisting Steroid Estrogens}

The simultaneous and competitive degradation of SEs in the ultrasound/ $\mathrm{KMnO}_{4}$ process was further investigated by serial pair combinations of E2, EE2, and E1 and results were showed in Figure 5 and Table 4. Some researches pointed out that an estrogenic coexisting system had more adverse influences on the ecological environment [7]. Additionally, it is supposed that coexisting SEs have mutual effects on each other in the decomposition process. Therefore, different coexisting combinations of estrogens (E2 and EE2; E2 and E1; EE2 and E1) were designed to summarize simultaneous or probable rules of competitive elimination and the impacts on each other. The concentration and percentage of each constituent were nearly identical to the experiments of the tri-coexisting SEs system.

Figure 5 shows that the initial concentrations of E2 and EE2 in dual-combination are 13.3 and $14.9 \mu \mathrm{g} \cdot \mathrm{L}^{-1}$, respectively, and the degradation ratios are $54.3 \%$ and $51.7 \%$ after $120 \mathrm{~min}$. The initial concentrations of EE2 and E1 are 14.8 and $19.4 \mu \mathrm{g} \cdot \mathrm{L}^{-1}$, respectively, and the degradation ratios of them are $53.0 \%$ and $49.2 \%$, respectively. The initial concentrations of E2 and E1 in dual-combination pattern are 10.9 and $16.1 \mu \mathrm{g} \cdot \mathrm{L}^{-1}$, respectively, and the degradation ratio of them are $55.6 \%$ and $50.7 \%$ after $120 \mathrm{~min}$ reaction.
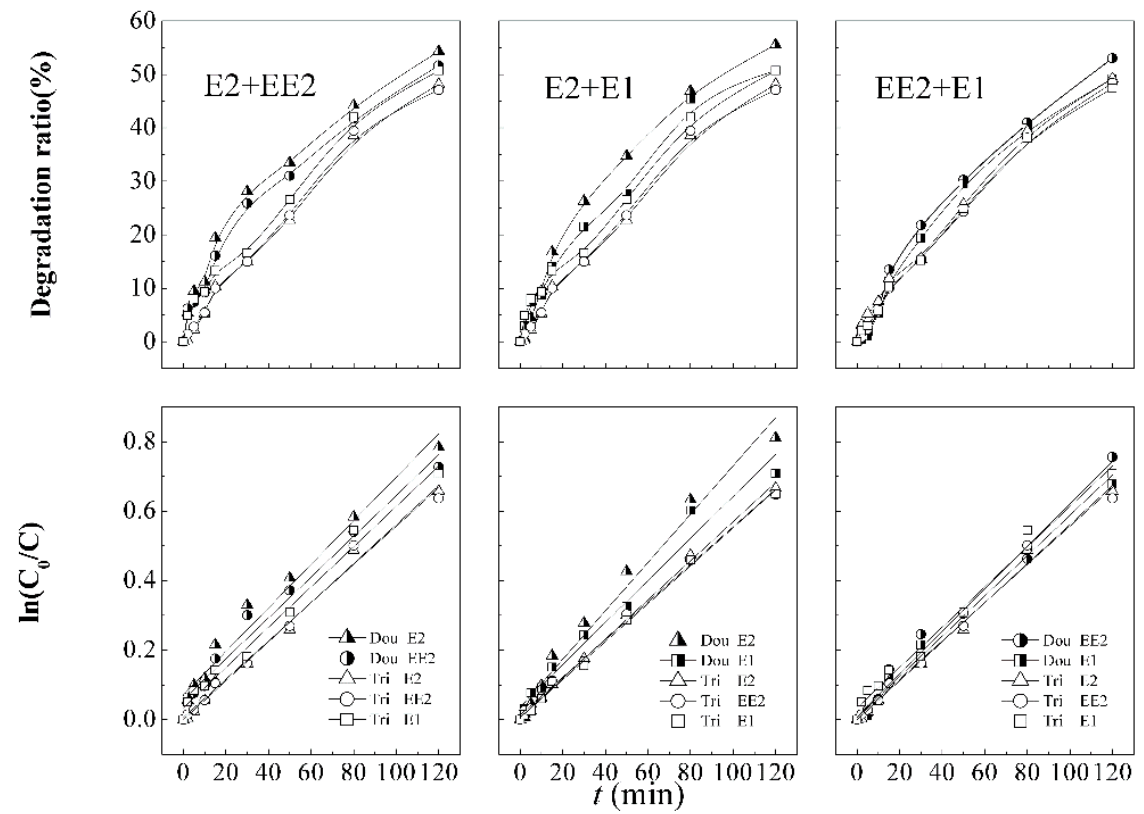

Figure 5. Degradation curves and first order kinetic models of dual- and tri-mixed SEs in the combination process.

Table 4. Parameters of degradation kinetic model of dual-mixed SEs.

\begin{tabular}{|c|c|c|c|c|c|}
\hline Combinations & Constituent & Kinetic Equation & $\begin{array}{c}\text { Reaction Rate } \\
\text { Constant } \mathrm{K} / \mathrm{min}^{-1}\end{array}$ & $\mathbf{R}^{2}$ & $\begin{array}{c}\text { Half-Life } \\
t_{1 / 2} / \min \end{array}$ \\
\hline \multirow{2}{*}{$\mathrm{E} 2+\mathrm{EE} 2$} & E2 & $\ln \left(\mathrm{C}_{0} / C\right)=0.0063 t+0.071$ & 0.0063 & 0.967 & 99 \\
\hline & EE2 & $\ln \left(\mathrm{C}_{0} / C\right)=0.0059 t+0.058$ & 0.0059 & 0.974 & 108 \\
\hline \multirow{2}{*}{ EE2+E1 } & EE2 & $\ln \left(\mathrm{C}_{0} / C\right)=0.0061 t+0.011$ & 0.0061 & 0.990 & 112 \\
\hline & E1 & $\ln \left(\mathrm{C}_{0} / C\right)=0.0058 t+0.008$ & 0.0058 & 0.992 & 118 \\
\hline \multirow{2}{*}{$\mathrm{E} 2+\mathrm{E} 1$} & E2 & $\ln \left(\mathrm{C}_{0} / C\right)=0.0070 t+0.035$ & 0.0070 & 0.997 & 94 \\
\hline & E1 & $\ln \left(\mathrm{C}_{0} / \mathrm{C}\right)=0.0061 t+0.038$ & 0.0061 & 0.996 & 107 \\
\hline
\end{tabular}

The results indicated that dual-combinations of E2, EE2, and E1 have better removal ratios than those in a tri-estrogens coexisting system, the degradation efficiency and reaction rate constant decrease with increasing numbers of constitute species and increasing total initial concentrations. The low concentration led to more effective degradation. In combined $\mathrm{KMnO}_{4} /$ ultrasounds, the generation of the free hydroxyl radicals $(\bullet \mathrm{OH})$ is accompanied with the consumption. When the 
parameters of the $\mathrm{KMnO}_{4} / \mathrm{ultrasound}$ process were fixed, the yield of $\bullet \mathrm{OH}$ was constant, and the collision probability between the molecules and $\bullet \mathrm{OH}$ increases when a lower amount of target compounds joined the competition.

\subsubsection{Steroid Estrogens Removal by $\mathrm{KMnO}_{4} /$ Ultrasound in Natural Water Background}

The competitive degradation for the tri-coexisting system occurring in raw surface water was studied, and the results were showed in Figure 6 and Table 6. The surface water was drawn from Shangtang River on campus, which had been pretreated by coagulation with PAC and sedimentation. The desired total concentration for target pollution is $50 \mu \mathrm{g} \cdot \mathrm{L}^{-1}$. The characteristic of the pretreated natural water is shown in Table 5.

Table 5. The water quality parameters of the pretreated natural water.

\begin{tabular}{cccccc}
\hline Turbidity (NTU) & Color (CU) & Temperature $\left({ }^{\circ} \mathbf{C}\right)$ & pH & TOC $\left(\mathbf{m g} \cdot \mathbf{L}^{-1}\right)$ & $\mathrm{UV}_{254}\left(\mathrm{~cm}^{-1}\right)$ \\
\hline 1.18 & 8 & 20 & 6.8 & 5.387 & 0.0396 \\
\hline
\end{tabular}

The comparison of SEs removal efficiency in different backgrounds is shown in Figure 6. The degradation of E2 (49.2\%), EE2 (48.4\%), and E1 (47.4\%) in pure water is lower than of E2 (61.8\%), EE2 $(56.5 \%)$, and E1 (60.8\%) in natural water. The advantage was also reflected by the first order kinetic constants, with $0.00562 \mathrm{~min}^{-1}$ (E2), $0.00546 \mathrm{~min}^{-1}$ (EE2), $0.00563 \mathrm{~min}^{-1}$ (E1) of pure water and $0.00814 \mathrm{~min}^{-1}$ (E2), $0.00671 \mathrm{~min}^{-1}$ (EE2), and $0.00774 \mathrm{~min}^{-1}$ (E1) of natural water, respectively. The results demonstrate significant superior degradation in natural water background compared with those in pure water systems under the same process conditions.
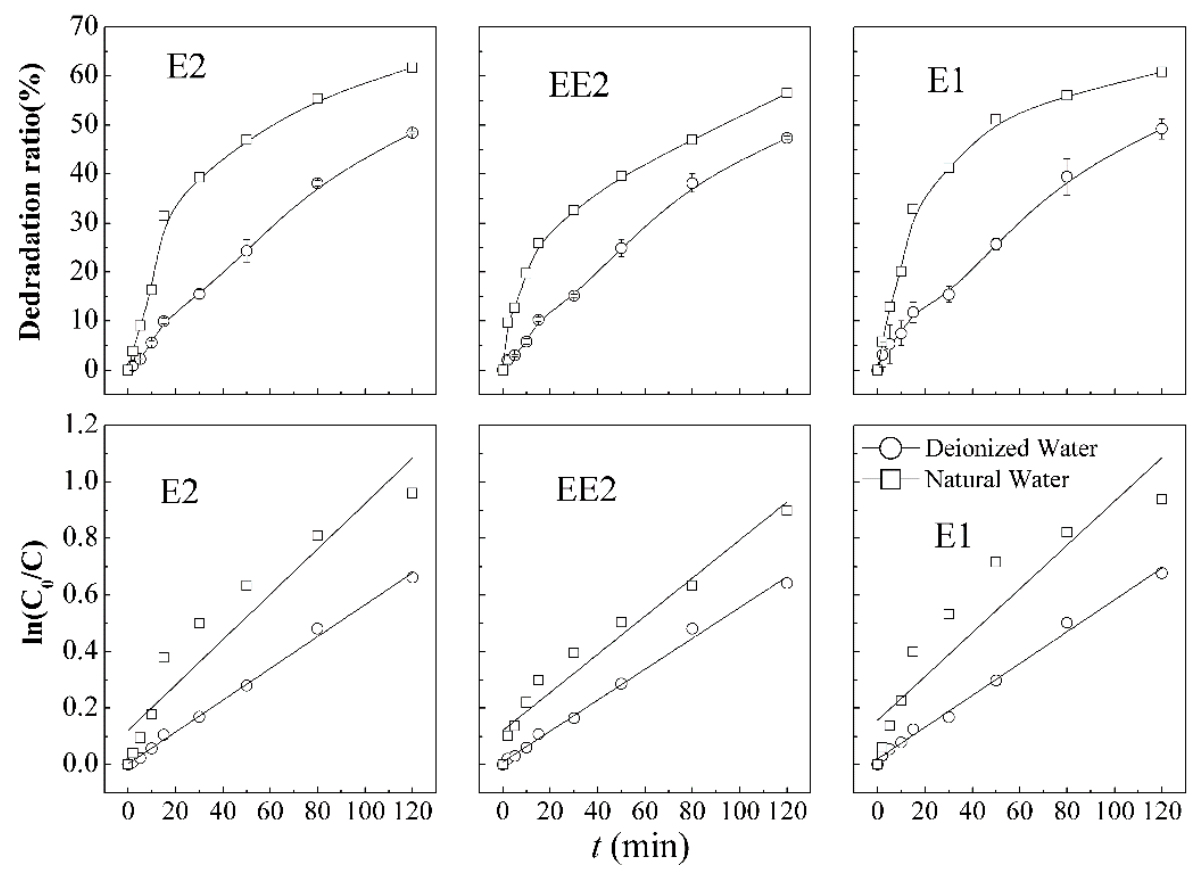

Figure 6. Steroid estrogens degradation curves and first order kinetic models in combination process under different aqueous background. 
Table 6. Parameters of kinetic model of degradation of steroid estrogens under different aqueous background.

\begin{tabular}{|c|c|c|c|c|c|}
\hline $\begin{array}{l}\text { Steroid } \\
\text { Estrogens }\end{array}$ & Backgrounds & Kinetic Equation & $\begin{array}{c}\text { Reaction Rate } \\
\text { Constant K/min }\end{array}$ & $\mathbf{R}^{2}$ & $\begin{array}{c}\text { Half- } \\
\text { Life } \\
t_{1 / 2} / \mathrm{min}\end{array}$ \\
\hline \multirow{2}{*}{ E2 } & Pure water & $\ln \left(\mathrm{C}_{0} / C\right)=0.0056 t+0.003$ & 0.0056 & 0.996 & 123 \\
\hline & Natural water & $\ln \left(\mathrm{C}_{0} / C\right)=0.0080 t+0.122$ & 0.0080 & 0.888 & 71 \\
\hline \multirow{2}{*}{ EE2 } & Pure water & $\ln \left(\mathrm{C}_{0} / C\right)=0.0055 t+0.010$ & 0.0055 & 0.994 & 124 \\
\hline & Natural water & $\ln \left(\mathrm{C}_{0} / C\right)=0.0067 t+0.121$ & 0.0067 & 0.944 & 100 \\
\hline \multirow{2}{*}{ E1 } & Pure water & $\ln \left(\mathrm{C}_{0} / \mathrm{C}\right)=0.0056 t+0.020$ & 0.0056 & 0.993 & 120 \\
\hline & Natural water & $\ln \left(\mathrm{C}_{0} / \mathrm{C}\right)=0.0077 t+0.157$ & 0.0077 & 0.867 & 70 \\
\hline
\end{tabular}

In the natural water simulation system, the removal of estrogens increased significantly. The reason might be the presence of background components, including dissolved organic matter (DOM), cations, anions, organics etc., enhancing the oxidation of estrogens by permanganate [44]. DOM was reported to generate photo-oxidants that can accelerate organic contaminants when irradiated at a solar wavelength of $254 \mathrm{~nm}$ [45]. The common bicarbonate ions were reported to be favorable in the elimination of micro-pollutants through carbonate radical producing, which can migrate towards the bulk of the solution and therefore induce the degradation, unlike the HO-radicals [46].

In a natural aquatic environment, the degradation rates of these three types of SEs increase prominently in 40 min compared with that of SEs in pure water, as illustrated in Figure 6, which also showed the removal rates decrease after that time point. Koyuncu et al. pointed out that when humic acid $\left(10 \mathrm{mg} \cdot \mathrm{L}^{-1}\right)$ was added to the feed solution, the removal of the hormones increased to approximately $95 \%$ or greater with slightly higher values observed for the hormones alone [47]. These observations of enhanced removal of hormones in raw water can be explained by the influence of natural organic matter. Shao et al. reported the degradation of E1 by permanganate in different backgrounds and found that the removal efficiency of E1 in natural water is significantly better than that in an ultra-pure water system. Pétrier et al. [46] found that bicarbonate ion present in natural waters was favorable in the elimination of micro-pollutants through carbonate radical producing. Therefore, humic acid, reducing substances $\left(\mathrm{SO}_{3^{2-}}, \mathrm{NO}^{2-}\right.$ et al.), complexes (EDTA, citrate, oxalate), $\mathrm{HCO}_{3}{ }^{-}$, phosphate et al. obviously can promote the oxidation of steroid estrogens; appropriate common ions in natural water such as $\mathrm{Mn}^{2+}, \mathrm{Fe}^{2+}$ and $\mathrm{Ca}^{2+}$ can enhance the removal of E1, slightly; however, $\mathrm{Al}^{3+}, \mathrm{Fe}^{3+}$ and $\mathrm{Mg}^{2+}$ inhibit the degradation of estrogens during the permanganate oxidation process [28,44].

In this experiment, coagulation with PAC $\left(5 \mathrm{mg} \cdot \mathrm{L}^{-1}\right)$ was used to pre-treat the raw water, so it is unavoidable that $\mathrm{Al}^{3+}$ ions will be introduced into the system. Investigation of the impact of $\mathrm{Al}^{3+}$ ions on SEs degradation in the combined process was conducted and the results are shown in Figure 7. The degradation of E2, EE2, and E1 decreases sharply to $24.9 \%, 25.8 \%$, and $26.5 \%$, respectively, after adding the coagulant PAC. The results indicated that coagulation of PAC exerts an inhibitory effect on the degradation, because the excess of $\mathrm{Al}^{3+}$ ions produced in coagulation by the hydrolysis of PAC $\left(\mathrm{Al}_{2}(\mathrm{OH})_{\mathrm{n}} \mathrm{Cl}_{6-\mathrm{n}}\right.$, enhanced by ultrasound) had an adverse effect on the oxidation by the combined $\mathrm{KMnO}_{4} /$ Ultrasound process, which is similar to the conclusion of Shao et al. [28].

The TOC values of the samples were collected at different times to measure the steroid estrogens' mineralizing degree by combined $\mathrm{KMnO}_{4} /$ ultrasound process.

The results (presented in Figure 8 and Table 7) indicate that direct mineralizing degrees are unsatisfactory, with the TOC removal rate of $20.2 \%$ and $16.6 \%$ in natural water and pure water, respectively. In the combined simultaneous degradation system, the $\mathrm{KMnO}_{4} /$ ultrasound process has effects on the removal of SEs, but still a large proportion of SEs remains. Instead, some intermediate products may be generated which still devote themselves to TOC. The oxidant capacity of $\bullet \mathrm{OH}$ and $\mathrm{KMnO}_{4}$ is insufficient to completely decompose the steroid estrogens. 

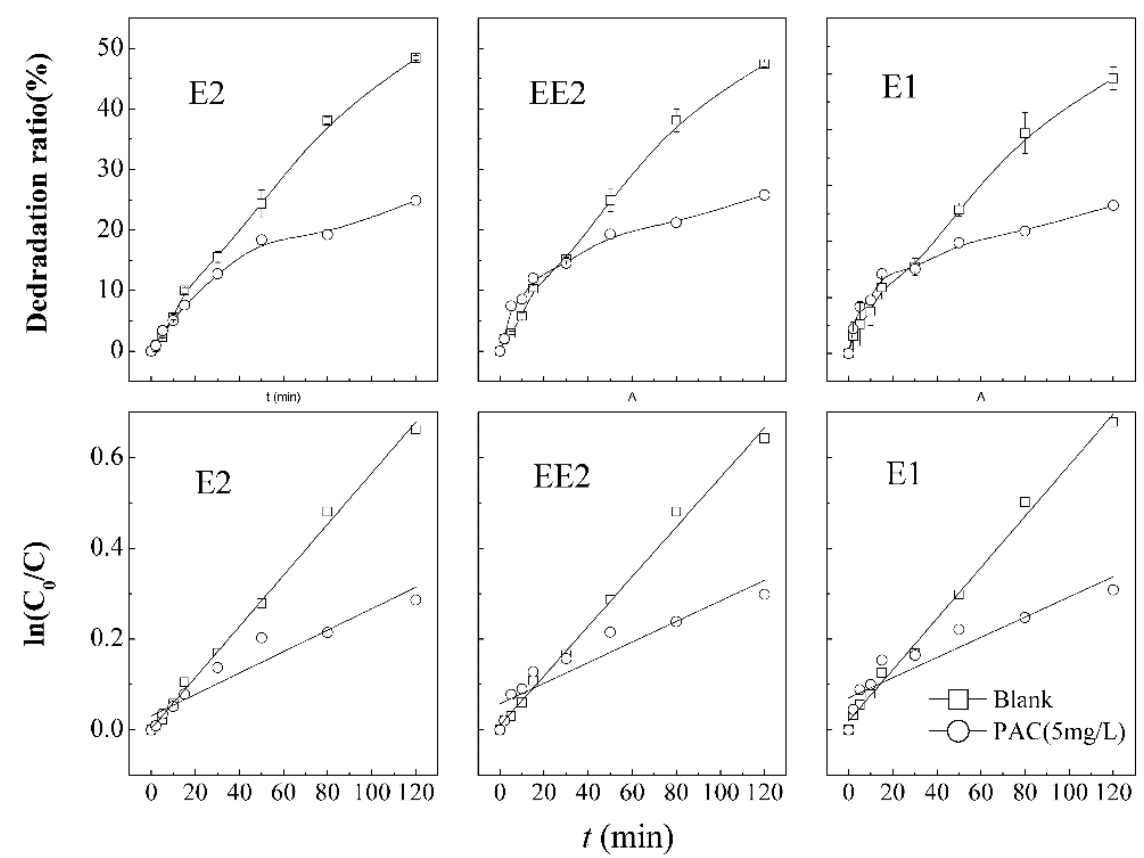

Figure 7. Degradation curves and first order kinetic models of SEs in the presence of $\mathrm{Al}^{3+}$.

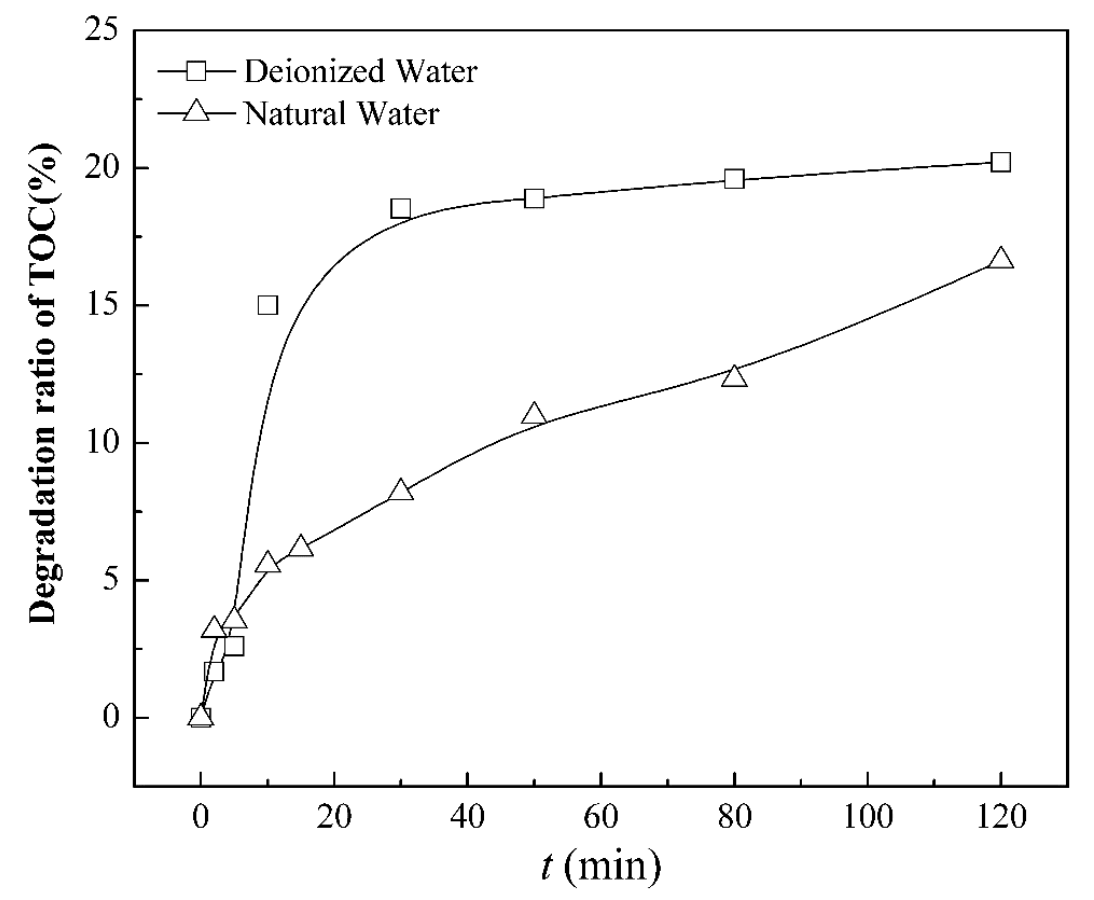

Figure 8. Mineralization of SEs indicated by $\mathrm{TOC}$ in $\mathrm{KMnO}_{4} /$ ultrasound process.

Table 7. Parameters of degradation kinetic model of SEs in the presence of $\mathrm{Al}^{3+}$.

\begin{tabular}{cccccc}
\hline $\begin{array}{c}\text { Steroid } \\
\text { Estrogens }\end{array}$ & $\begin{array}{c}\text { Comparison of } \\
\text { Condition }\end{array}$ & Kinetic Equation & $\begin{array}{c}\text { Reaction Rate } \\
\text { Constant K/min }\end{array}$ & $\mathbf{R}^{\mathbf{2}}$ & $\begin{array}{c}\text { Half-Life } \\
\boldsymbol{t}_{\mathbf{1} 2} / \mathbf{m i n}^{\mathbf{m}}\end{array}$ \\
\hline \multirow{2}{*}{$\mathrm{E} 2$} & Blank sample & $\ln \left(\mathrm{C}_{0} / C\right)=0.0056 t+0.003$ & 0.0056 & 0.9962 & 123 \\
& Addition to PAC & $\ln \left(\mathrm{C}_{0} / C\right)=0.0024 t+0.031$ & 0.0024 & 0.9057 & 281 \\
\hline \multirow{2}{*}{ EE2 } & Blank sample & $\ln \left(\mathrm{C}_{0} / C\right)=0.0055 t+0.010$ & 0.0055 & 0.9939 & 125 \\
& Addition to PAC & $\ln \left(\mathrm{C}_{0} / C\right)=0.0023 t+0.057$ & 0.0023 & 0.8526 & 281 \\
\hline \multirow{2}{*}{ E1 } & Blank sample & $\ln \left(\mathrm{C}_{0} / C\right)=0.0056 t+0.020$ & 0.0056 & 0.9931 & 120 \\
& Addition to PAC & $\ln \left(\mathrm{C}_{0} / C\right)=0.0022 t+0.070$ & 0.0022 & 0.8337 & 280 \\
\hline
\end{tabular}




\section{Conclusions}

Steroid estrogens (E2, EE2, and E1) in mixed aqueous systems can partly be removed by single $\mathrm{KMnO}_{4}$ and pure ultrasound irradiation, which are both less effective than oxidation by the combined $\mathrm{KMnO}_{4} / \mathrm{ultrasound}$ technique. In combined treatment processes, at a low initial concentration of $\mu \mathrm{g} / \mathrm{L}$, there was almost no significant competition of degradation between coexisting SEs.

The combined $\mathrm{KMnO}_{4} /$ ultrasound process can remove the coexisting three steroid estrogens from an aqueous system more effectively as compared to the single processes. E2, EE2, and E1 in dual-combined simulated pollution show better removal efficiency than those in tri-estrogens coexisting systems. The degradation rates of SEs were significantly accelerated in a natural water background, which suggests that combined processes have prospective application in surface water treatment. However, it should be taken into consideration that $\mathrm{Al}^{3+}$ generated from coagulation has a negative effect on enhanced oxidation.

Further, with regard to coexisting SEs in water, it is not enough to focus on the degradation rate or removal efficiencies; more "sophisticated" toxicity tests, such as YES (yeas estrogen screen), and estrogenicity tests are needed in order to demonstrate the efficiency of a process.

Acknowledgments: This research is supported by National natural Science Foundation of China (Grant No. 51208468, 51208469 and No. 51378446), Open fund of priority subject of Zhejiang province (Grant No.20130307), Open fund of Environmental Science and Engineering of Jiangsu (Grant No.Zd131202), the Natural Science Foundation of Fujian Province of China (Grant No. 2013J01212), Program for New Century Excellent Talents in Fujian Province University (Grant No. JA14227) and Science, Technology Innovation Program for Undergraduate of Zhejiang Province (Grant No. 2014R403071) and Science and Technology Innovation Program for Undergraduate of Zhejiang Province (New Talents Program).

Author Contributions: The manuscript was written through contributions of all authors. Jing Deng conceived and designed the experiments; Kai Tang analyzed the data; Shijun Zhu performed the experiments and wrote the paper; Xiaoyan Ma designed the experiment and revised the paper; Kejia Zhang and Yali Song established the detection method; Xueyan Li and Qingsong Li contributed experimental apparatus and reagents; Zhenhua Liu and Kejin Zhou analyzed the data and revised the paper.

Conflicts of Interest: The authors declare no conflict of interest.

\section{Abbreviations:}

Steroid estrogens (SEs); estrone (E1); 17 $\beta$-estradiol (E2); $17 \alpha$-ethinyl estradiol (EE2); solid phase extraction (SPE).

\section{References}

1. Hanselman, T.A.; Graetz, D.A.; Wilkie, A.C. Manure-borne estrogens as potential environmental contaminants: A review. Environ. Sci. Technol. 2003, 37, 5471-5478.

2. Esteban, S.; Gorga, M.; Petrovic, M.; Gonzalez, A.S.; Barcelo, D.; Valcarcel, Y. Analysis and occurrence of endocrine-disrupting compounds and estrogenic activity in the surface waters of Central Spain. Sci. Total Environ. 2014, 466, 939-951.

3. Sun, Y.; Huang, H.; Sun, Y.; Chao, W.; Shi, X.L.; Hu, H.Y.; Kameya, T.; Fujie, K. Ecological risk of estrogenic endocrine disrupting chemicals in sewage plant effluent and reclaimed water. Environ. Pollut. 2013, 180, 339-344.

4. Tapiero, H.; Ba, G.N.; Tew, K. Estrogens and environmental estrogens. Biomed. Harmacother. 2002, 56, $36-44$.

5. Xu, L.; Xu, C.; Zhao, M.R.; Qiu, Y.P.; Sheng, G.D. Oxidative removal of aqueous steroid estrogens by manganese oxides. Water Res. 2008, 42, 5038-5044.

6. Yang, J. The Removal of Two Kinds of Emerging Compounds in Aqueous Solution by Permanganate. PhD Thesis, Harbin Institute of Technology, Harbin, China, 2011.

7. Zhang, Z. Removal mechanisms and combined pollution effect of estrogens in urban water body. PhD Thesis. Harbin Institute of Technology, Harbin, China, 2010. 
8. Zheng, W.; Li, X.; Yates, S.R.; Bradford, S.A. Anaerobic transformation kinetics and mechanism of steroid estrogenic hormones in dairy lagoon water. Environ. Sci. Technol. 2012, 46, 5471-5478.

9. Ying, G.G.; Kookana, R.S.; Ru, Y.J. Occurrence and fate of hormone steroids in the environment. Environ. Int. 2002, 28, 545-551.

10. Chang, H.; Hu, J.Y.; Shao, B.; Xu, Y.; Gao, J.F.; Dong, M.Q. Dermination of trace estrogens in surface water suing SPE-LC-MS. Environ. Chem. 2003, 22, 400-403.

11. Kuch, H.M.; Ballschmiter, K. Determination of endocrine-disrupting phenolic compounds and estrogens in surface and drinking water by HRGC-(NCI)-MS in the picogram per liter range. Environ. Sci. Technol. 2001, 35, 3201-3206.

12. Nie, M.H.; Yang, Y.; Liu, M.; Yan, C.X.; Dong, W.B.; Zhou, J.L. Environmental estrogens in a drinking water reservoir area in Shanghai: Occurrence, colloidal contribution and risk assessment. Sci. Total Environ. 2014, 487, 785-791.

13. Babel, S.; Kurniawan, T.A. Low-cost adsorbents for heavy metals uptake from contaminated water: A review. J. Hazard. Mater. 2003, 97, 219-243.

14. Fukuhara, T.; Iwasaki, S.; Kawashima, M.; Shinohara, O.; Abe, I. Absorbability of estrone and 17beta-estradiol in water onto activated carbon. Water Res. 2006, 40, 241-248.

15. Rivera, U.J.; Sánchez, P.M.; Gómez, S.V.; Álvarez, P.M.; Alvim, F.M.C.; Dias, J.M. Activated carbon modifications to enhance its water treatment applications. An overview. J. Hazard. Mater. 2011, 187, 1-23.

16. Yoon, Y.; Westerhoff, P.; Snyder, S.A.; Esparza, M. HPLC-fluorescence detection and adsorption of bisphenol A, 17 $\beta$-estradiol, and 17 $\alpha$-ethynyl estradiol on powdered activated carbon. Water Res. 2003, 37, 3530-3537.

17. Zhang, Y.P.; Zhou, J.L. Removal of estrone and 17beta-estradiol from water by adsorption. Water Res. 2005, 39, 3991-4003.

18. Pholchan, P.; Jones, M.; Donnelly, T.; Sallis, P.J. Fate of estrogens during the biological treatment of synthetic wastewater in a nitrite-accumulating sequencing batch reactor. Environ. Sci. Technol. 2008, 42, 6141-6147.

19. Rokhina, E.V.; Suri, R.P.S. Application of density functional theory (DFT) to study the properties and degradation of natural estrogen hormones with chemical oxidizers. Sci. Total Environ. 2012, 417, 280-290.

20. Feng, Y.J.; Wang, C.; Liu, J.F.; Zhang, Z.H. Electrochemical degradation of 17-alpha-ethinylestradiol (EE2) and estrogenic activity changes. J. Environ. Monitor. 2010, 12, 404-408.

21. Frontistis, Z.; Xekoukoulotakis, N.P.; Hapeshi, E.; Venieri, D.; Fatta-Kassinos, D.; Mantzavinos, D. Fast degradation of estrogen hormones in environmental matrices by photo-Fenton oxidation under simulated solar radiation. Chem. Eng. J. 2011, 178, 175-182.

22. Rudder, J.D.; Wiele, T.V.D.; Dhooge, W.; Comhaire, F.; Verstraete, W. Advanced water treatment with manganese oxide for the removal of $17 \alpha$-ethynylestradiol (EE2). Water Res. 2004, 38, 184-192.

23. Zhang, W.L.; Li, Y.; Wang, C.; Wang, P.F.; Wang, Q.; Wang, D.W. Mechanisms of simultaneous hydrogen production and estrogenic activity removal from secondary effluent though solar photocatalysis. Water Res. 2013, 47, 3173-3182.

24. Silva, C.P.; Otero, M.; Esteves, V. Processes for the elimination of estrogenic steroid hormones from water: A review. Environ. Pollut. 2012, 165, 38-58.

25. Ma, X.Y.; Tang, K.; Li, Q.S.; Song, Y.L.; Ni, Y.J.; Gao, N.Y. Parameters on 17ß-Estradiol degradation by Ultrasound in an aqueous system. J. Chem. Technol. Biotechnol. 2014, 89, 322-327.

26. Li, G.B.; Yang, Y.L.; Ma, J.; Qu, J.H. Research on mechanism of removal of microorganic pollutants in natural water by permanganate. J. Dalian Railway Institute. 1998, 19, 1-4. (In Chinese).

27. Aleboyeh, A.; Olya, M.E.; Aleboyeh, H. Oxidative treatment of azo dyes in aqueous solution by potassium permanganate. J. Hazard. Mater. 2009, 162, 1530-1535.

28. Shao, X. Fate and Occurrence of Endocrine Disrupting Chemicals in Urban Aquatic Environment and the Control by Permanganate Oxidation. PhD Thesis. Harbin Institute of Technology, Harbin, China, 2009.

29. Zhang, J.; Li, G.B. Removal of phenol from water by potassium permanganate. J. Harbin Univ. Civ. Eng. Archit. 2002, 35, 66-69. (In Chinese).

30. Frontistis, Z.; Mantzavinos, D. Sonodegradation of 17alpha-ethynylestradiol in environmentally relevant matrices: Laboratory-scale kinetic studies. Ultrason. Sonochem. 2012, 19, 77-84.

31. Olson, T.M.; Barbier, P.F. Oxidation kinetics of natural organic matter by sonolysis and ozone. Water Res. 1994, 28, 1383-1391. 
32. Thompson, L.H.; Doraiswamy, L.K. Sonochemistry: Science and engineering. Ind. Eng.Chem. Res. 1999, 38, 1215-1249.

33. Yao, J.J.; Gao, N.Y.; Li, C.; Li, L.; Xu, B. Mechanism and kinetics of parathion degradation under ultrasonic irradiation. J. Hazard. Mater. 2010, 175, 138-145.

34. Zhang, D.B.; Zhang, H.; Duan, L.J. Absorption kinetics of ozone in water with ultrasonic radiation. Ultrason. Sonochem. 2007, 14, 552-556.

35. Gonze, E.; Fourel, L.; Gonthier, Y.; Boldo, P.; Bernis, A. Wastewater pretreatment with ultrasonic irradiation to reduce toxicity. Chem. Eng. J. 1999, 73, 93-100.

36. Fu, H.X.; Suri, R.P.S.; Chimchirian, R.F.; Helmig, E.; Constable, R. Ultrasound-induced destruction of low levels of estrogen hormones in aqueous solutions. Environ. Sci. Technol. 2007, 41, 5869-5874.

37. Qiu, L.P.; Wang, W.K. Mechanism and efficiency of nitrobenzene degradation in underground water by ultrasound-potassium permanganate. Ind. Saf. Environ. Prot. 2012, 38, 1-5.

38. Lesko, T.; Colussi, A.J.; Hoffmann, M.R. Sonochemical decomposition of phenol: Evidence for a synergistic effect of ozone and ultrasound for the elimination of total organic carbon from water. Environ. Sci. Technol. 2006, 40, 6818-6823.

39. Weavers, L.K.; Hoffmann, M.R. Sonolytic decomposition of ozone in aqueous solution: Mass transfer effects. Environ. Sci. Technol. 1998, 32, 3941-3947.

40. Weavers, L.K.; Ling, F.H.; Hoffmann, M.R. Aromatic compound degradation in water using a combination of sonolysis and ozonolysis. Environ. Sci. Technol. 1998, 32, 2727-2733.

41. Ma, X.Y.; Tang, K.; Li, Q.S.; Song, Y.L.; Ni, Y.J.; Gao, N.Y. Degradation of $17 \beta$-estradiol by combined ultrasound/KMnO 4 in an aqueous system. Desalination Water Treat. 2013, 53, 493-500.

42. Frontistis, Z.; Daskalaki, V.M.; Hapeshi, E.; Drosou, C.; Fatta-Kassinos, D.; Xekoukoulotakis, N.P.; Mantzavions, D. Photocatalytic (UV-A/TiO $)$ degradation of $17 \alpha$-ethynylestradiol in environmental matrices: Experimental studies and artificial neural network modeling. J. Photochem. Photobiol. A Chem. 2012, 240, 33-41.

43. He, S.; Zhu, C.; Shan, M.; Feng, R. Recent advances in wastewater treatment with ultrasonic-ozone method. Tech. Acoust. 2005, 24, 173-177. (In Chinese).

44. Shao, X.; Ma, J.; Wen, G.; Yang, J. Oxidation of estrone by permanganate: Reaction kinetics and estrogenicity removal. Chinese Sci. Bull. 2010, 55, 802-808.

45. Lester, Y.; Sharpless, C.M.; Mamane, H.; Linden, K.G. Production of photo-oxidants by dissolved organic matter during UV water treatment. Environ. Sci. Technol. 2013, 47, 11726-11733

46. Pétrier, C.; Torres-Palma, R.; Combet, E.; Sarantakos, G.; Baup, S.; Pulgarin, C. Enhanced sonochemical degradation of bisphenol-A by bicarbonate ions. Ultrason. Sonochem. 2010, 17, 111-115.

47. Koyuncu, I.; Arikan, O.A.; Wiesner, M.R.; Rice, C. Removal of hormones and antibiotics by nanofiltration membranes. J. Membr. Sci. 2008, 309, 94-101.

(C) 2015 by the authors; licensee MDPI, Basel, Switzerland. This article is an open access article distributed under the terms and conditions of the Creative Commons by Attribution (CC-BY) license (http://creativecommons.org/licenses/by/4.0/). 